Portland State University

PDXScholar

TREC Final Reports

Transportation Research and Education Center

(TREC)

9-1-2019

\title{
Developing Data, Models, and Tools to Enhance Transportation Equity
}

Amy Lubitow

Portland State University

Raoul Liévanos

University of Oregon

Julius McGee

Portland State University

Erika Carpenter

Portland State University

Follow this and additional works at: https://pdxscholar.library.pdx.edu/trec_reports

Part of the Transportation Commons

Let us know how access to this document benefits you.

\section{Recommended Citation}

Lubitow, Amy; Liévanos, Raoul, McGee, Julius \& Carpenter, Erika. Developing Data, Models, and Tools to Enhance Transportation Equity. NITC-RR-1122. Portland, OR: Transportation Research and Education Center (TREC), 2019. https://doi.org/10.15760/trec.239

This Report is brought to you for free and open access. It has been accepted for inclusion in TREC Final Reports by an authorized administrator of PDXScholar. Please contact us if we can make this document more accessible: pdxscholar@pdx.edu. 


\section{DEVELOPING DATA, MODELS, AND TOOLS TO ENHANCE TRANSPORTATION EQUITY \\ Limitations and Opportunities in Household Travel Survey Methods}

\section{Final Report}

\section{NITC-RR-1122}

by

Amy Lubitow, 0000-0002-9019-9871, Portland State University

Raoul Liévanos, 0000-0002-3647-1504, University of Oregon Julius McGee, 0000-0002-2087-6865, Portland State University

Erika Carpenter, Portland State University

\section{for}

National Institute for Transportation and Communities (NITC)

P.O. Box 751

Portland, OR 97207

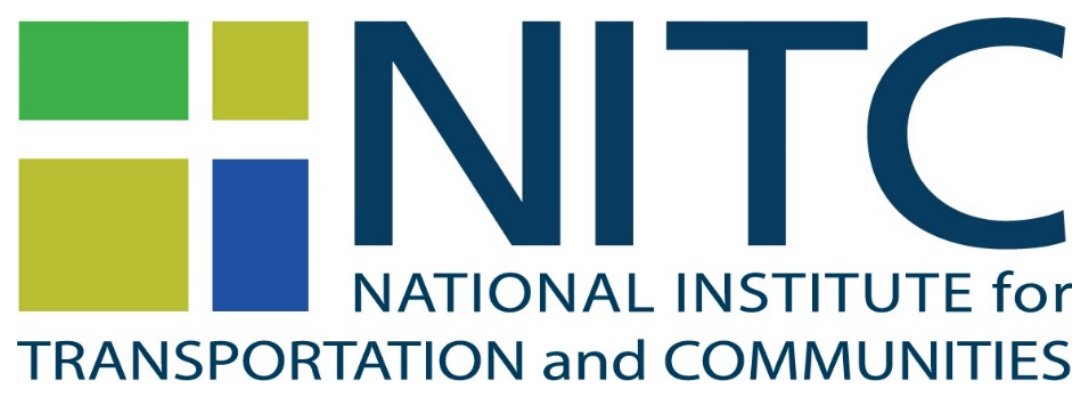

September 2019 


\begin{tabular}{|c|c|c|c|c|}
\hline \multicolumn{5}{|c|}{ Technical Report Documentation Page } \\
\hline $\begin{array}{l}\text { 1. Report No. } \\
\text { NITC-RR-1122 }\end{array}$ & \multicolumn{2}{|c|}{ 2. Government Accession No. } & \multicolumn{2}{|c|}{ 3. Recipient's Catalog No. } \\
\hline \multirow{2}{*}{\multicolumn{4}{|c|}{$\begin{array}{l}\text { 4. Title and Subtitle } \\
\text { Developing Data, Models, and Tools to Enhance Transportation Equity }\end{array}$}} & \\
\hline & & & & 6. Performing Organization Code \\
\hline \multicolumn{3}{|c|}{$\begin{array}{l}\text { 7. Author(s) } \\
\text { Amy Lubitow, Raoul Liévanos, Julius McGee, Erika Carpenter }\end{array}$} & \multicolumn{2}{|c|}{ 8. Performing Organization Report No. } \\
\hline \multirow{2}{*}{\multicolumn{4}{|c|}{ 9. Performing Organization Name and Address }} & 10. Work Unit No. (TRAIS) \\
\hline & & & & 11. Contract or Grant No. \\
\hline \multirow{2}{*}{\multicolumn{3}{|c|}{$\begin{array}{l}\text { 12. Sponsoring Agency Name and Address } \\
\text { National Institute for Transportation and Communities (NITC) } \\
\text { P.O. Box } 751 \\
\text { Portland, OR } 97207 \\
\end{array}$}} & \multicolumn{2}{|c|}{ 13. Type of Report and Period Covered } \\
\hline & & & & 14. Sponsoring Agency Code \\
\hline \multicolumn{5}{|c|}{ 15. Supplementary Notes } \\
\hline \multicolumn{5}{|c|}{$\begin{array}{l}\text { 16. Abstract } \\
\text { This project used a mixed-methods approach to data collection and analysis in the Portland, OR, metropolitan area. } \\
\text { It used quantitative techniques, the } 2010 \text { Decennial Census, and the } 2011 \text { Oregon Household Activity Survey to } \\
\text { assess how accurately travel survey data represent minority populations. These groups are of primary interest due } \\
\text { to their status as protected classes under Title VI of the Civil Rights Act, and accurate data on the mobility patterns } \\
\text { of these groups is essential to equitable transportation planning. Qualitative focus groups with residents in the } \\
\text { Portland metropolitan area investigated better methods for building equity into transportation surveys using } \\
\text { community input to critique existing survey methods while also collecting alternative approaches that are relevant } \\
\text { to community members. }\end{array}$} \\
\hline $\begin{array}{l}\text { 17. Key Words } \\
\text { Transportation equity, household travel } \\
\text { community-based research }\end{array}$ & S, underrepresented groups, & & $\begin{array}{l}\text { bution Statement } \\
\text { rictions. Copies avc } \\
\text { itc-utc.net }\end{array}$ & \\
\hline $\begin{array}{l}\text { 19. Security Classification (of this report) } \\
\text { Unclassified }\end{array}$ & $\begin{array}{l}\text { 20. Security Classification } \\
\text { Unclassified }\end{array}$ & page) & 21. No. of Pages & 22. Price \\
\hline
\end{tabular}




\section{ACKNOWLEDGEMENTS}

The research team would like to acknowledge partial support from the National Institute for Transportation and Communities (NITC \#1122), a U.S. DOT University Transportation Center, and the support of the Portland State University Institute for Sustainable Solutions

\section{DISCLAIMER}

The contents of this report reflect the views of the authors, who are solely responsible for the facts and the accuracy of the material and information presented herein. This document is disseminated under the sponsorship of the U.S. Department of Transportation University Transportation Centers Program in the interest of information exchange. The U.S. Government assumes no liability for the contents or use thereof. The contents do not necessarily reflect the official views of the U.S. Government. This report does not constitute a standard, specification, or regulation.

\section{RECOMMENDED CITATION}

Lubitow, Amy; Liévanos, Raoul, McGee, Julius \& Carpenter, Erika. Developing Data, Models, and Tools to Enhance Transportation Equity. NITC-RR-1122. Portland, OR: Transportation Research and Education Center (TREC), 2019. 
TABLE OF CONTENTS

DEVELOPING DATA, MODELS, AND TOOLS TO ENHANCE TRANSPORTATION EQUITY

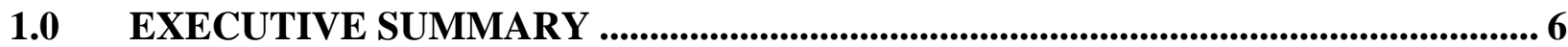

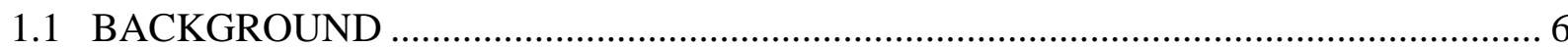

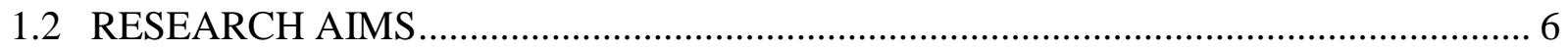

1.2.1 Equity Limitations of the Oregon Household Activity Survey .................................. 7

1.2.2 Enhancing Equity in Transportation Survey Research ............................................... 7

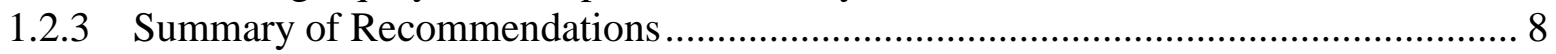

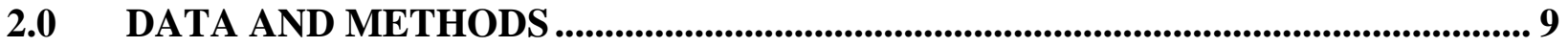

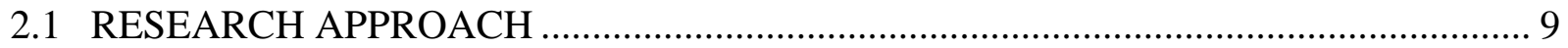

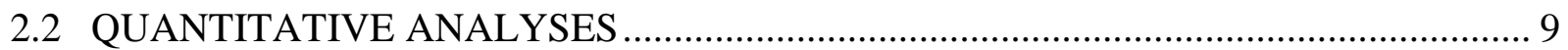

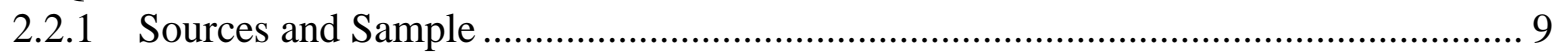

2.2.2 Assessing Racial Representation in the 2011 OHAS .............................................. 10

2.2.3 Assessing the Relationship Between the 2011 OHAS Household Response Rate and

Householder Racial Identity ............................................................................................ 11

2.2.4 Identifying Sites for Focus Group Research ........................................................ 12

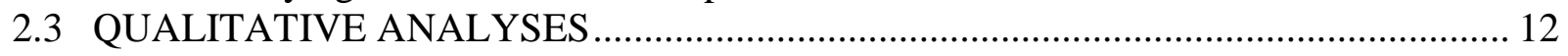

2.3.1 Focus Group Process........................................................................................... 12

2.3.2 Focus Group Participant Recruitment.............................................................. 13

2.3.3 Focus Group Sample.............................................................................................. 14

2.3.4 Qualitative Data Analysis Procedures ....................................................................... 14

2.3.5 Additional Data Collection: English as a Second Language Community Partnership 15

3.0 QUANTITATIVE FINDINGS..................................................................................... 17

3.1 RACIAL REPRESENTATION IN THE 2011 OHAS ................................................. 17

3.2 OHAS HOUSEHOLD RESPONSE RATE AND BIVARIATE CORRELATIONS ...... 19

3.3 SITES FOR FOCUS GROUP RESEARCH............................................................ 21

4.0 QUALITATIVE FINDINGS ........................................................................................... 23

4.1 LIMITATIONS OF ONE-DAY TRAVEL DIARY ……………................................ 23

4.2 BARRIERS TO ONE-DAY TRAVEL DIARY COMPLETION ……………................ 23

4.2.1 Privacy Concerns as a Barrier............................................................................... 23

4.2.2 Time Investment as a Barrier................................................................................. 24

4.2.3 Discrimination and Racism as Barriers to Survey Completion ................................. 25

4.2.4 Language Barriers ...................................................................................................... 28

5.0 CONCLUSION: RECOMMENDATIONS TO ENHANCE EQUITY IN

TRANSPORTATION SURVEY RESEARCH...................................................................... 30

5.1.1 Transparency in Data Collection ....................................................................... 30

5.1.2 Protection of Data and Privacy ………………......................................................... 30

5.1.3 Community Engagement Throughout Data Collection Process ................................. 30

5.1.4 Reduce Language Barriers ...................................................................................... 31

5.1.5 Collecting Travel Behavior Data Via GPS Technology ............................................ 31

5.1.6 Suggestions for Enhancing Access to Travel Survey Research Amongst Those with

Limited English Proficiency ................................................................................................. 32

5.1.6.1 Design Elements............................................................................................. 33 
5.1.6.2 Specific Phrasing Suggestions .......................................................................... 33

5.1.6.3 Personal Information Concerns..................................................................... 34

5.1.7 Concluding Thoughts................................................................................................... 34

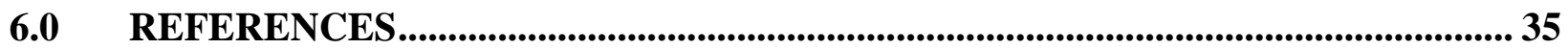

\section{LIST OF TABLES}

Table 1.1: Recommendations for Enhancing Transportation Survey Methods ......................................................8

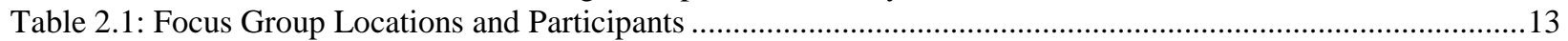

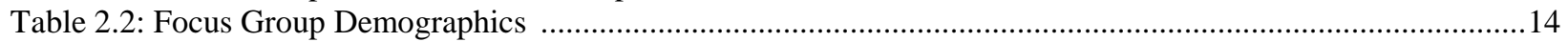

Table 3.1: Kendall Tau-b Correlation Coefficients for the Association Between the 2011 OHAS Household

Response Rate and 2010 Decennial Census Householder Racial Identification ..............................................21

Table 3.2: Descriptive Statistics for the 2011 OHAS Household Response Rate and the 2010 Householder

Latinx/Nonwhite Identification in Tracts Intersecting the One-Kilometer Buffer to Focus Group Location ...22

\section{LIST OF FIGURES}

Figure 1.1. County and Tract Boundaries in the Portland Metropolitan Study Area..... 10

Figure 3.1. Aggregate Percent of Households by Householder Racial Identification in the 2010 Census and the 2011 Oregon Household Activity Survey (OHAS) in 457 Census Tracts Within the Four-County Portland Metropolitan Study Area.

Figure 3.2. Tract-Level Average Percent of Households by Householder Racial Identification in the 2010 Census and the 2011 Oregon Household Activity Survey (OHAS) in 457 Census Tracts Within the Four-County Portland Metropolitan Study Area

Figure 3.3. Quartiles of Tract-Level Percent of Households that Responded to the 2011 Oregon Household Activity

Survey (OHAS) in the Four-County Portland Metropolitan Study Area .........................................................20

Figure 3.4. Focus Group Locations and Their One-Kilometer Buffer in Map (A) of the Four-County Portland Metropolitan Study Area and in Map (B) of Portland City and Vicinity 


\subsection{EXECUTIVE SUMMARY}

\subsection{BACKGROUND}

Despite recent improvements in transportation accessibility assessments and transportation survey methodologies, there are still challenges in engaging hard-to-reach populations in transportation surveys, such as low-income, minority, and transit-dependent populations that are protected classes under Title VI of the Civil Rights Act and Executive Order 12898. Because travel survey data are used to forecast demand, inform transportation investments, and craft urban policies, it is critical to understand how the travel behavior of these populations is reflected in survey data (Karner and Niemeier, 2013; Martens, Golub and Robinson, 2012; Forkenbrock and Schweitzer, 1999). Gaps between data collection and analytical techniques may lead to underrepresentation of disadvantaged populations and the extent of their transportation accessibility in transportation surveys, which could in turn impede policy implementation related to transportation equity.

The quality of travel behavior data is a central issue to transportation equity analyses and broader transportation planning. Martens (2017) suggests, however, that the use of travel behaviors and activity as a means of forecasting travel service provision is ineffective and inappropriate because current behaviors reflect constrained choices, not true demand. More specific limitations in travel survey methodologies include the routine variation in travel behaviors that is missed by the commonly used single-day activity survey (Rizzo and Erhardt, 2016), as well as the potential for misclassification of responses to survey questions (Paleti and Balan, 2017). Exacerbating these challenges is the ongoing underrepresentation of low-income, minority, and transitdependent communities in survey data, as survey participation may be difficult to secure for a variety reasons (i.e., language, telephone access, concerns about responding to government surveys, lack of time) (Shaghaghi et al., 2011; Tourangeau, 2014). These groups have not been adequately represented in past data collection efforts and, thus, their behaviors and needs are not fully understood (Riandey and Quaglia, 2009).

This is particularly problematic as the Federal Transportation Administration (FTA) recognizes racial and ethnic minorities as a protected class, and it requires transit agencies to demonstrate that policies and fare changes do not disproportionately impact low-income populations (FTA, 2012). Karner and Niemeier (2013) uncover methodological issues in regional transportation equity analyses (see also Selby et al., 2017). Specifically, they find that the standard practice of equity analysis obscures how transportation accessibility varies by the racial status of economically disadvantaged and transit-dependent individuals, households, and place-based communities at various geographic scales. The primary aims of this study are to explore these concerns using both quantitative and qualitative methodologies in the Portland, OR, metropolitan area.

\subsection{RESEARCH AIMS}

Building upon previous scholarship, this study aims to: 
(1) Explore how different racial groups are represented in transportation survey data in Portland and;

(2) Engage marginalized populations in Portland to ascertain how best to increase survey completion amongst underrepresented groups

\subsubsection{Equity Limitations of the Oregon Household Activity Survey}

Despite recent improvements in household transportation survey methodologies, people of color and immigrant groups remain undersampled and understudied (referred to in quantitative findings as "Nonwhite" or by a specific racial identity). The limited survey coverage and responses of these populations may lead to inaccurate estimation of their transportation access and behavior and to a broader problem of racial misrepresentation in transportation survey data.

In this report, we linked 2010 census population and housing data to an apparent stratified random sample of 6,107 household responses to the 2011 Oregon Household Activity Survey (OHAS) in the Portland metropolitan area. We found that the 2011 OHAS consistently overrepresented White households and underrepresented Nonwhite households in aggregate and at the tract level across the greater Portland area. Further, we found that, on average at the tract level, the percentages of Latinx and Nonwhite householders are significantly and negatively associated with 2011 OHAS household response rates.

We then identified census tracts where OHAS household response rates were low and where Nonwhite racial composition was high. Those tracts were selected for in-depth qualitative research summarized in Section 1.2.2 and Section 4 of this report.

\subsubsection{Enhancing Equity in Transportation Survey Research}

In an effort to attend to research aim number two, more than 50 Portland-area residents who are low-income and/or identify as racial or ethnic minorities were recruited to participate in a twohour focus group that discussed the OHAS's travel diary, as well as their general interest or likelihood in participating in a household activity survey.

Focus groups were convened after quantitative analyses of OHAS data revealed spatial inequities in survey response rates. Neighborhoods that were underrepresented in the quantitative data were selected as prime locations for hosting a focus group. Participants were recruited to participate through partnerships the PI developed with local organizations in the targeted areas. A total of six focus groups were convened with a total of 57 participants. Key findings demonstrate that marginalized groups (in this case, immigrants and those who do not speak English as their first language, people of color, and low-income individuals) face significant barriers to completing household transportation surveys. Language barriers, time constraints, concerns about personal privacy, mistrust of the government, and issues with the construction of the survey questions themselves were all found to be significant issues across all of our focus groups. 


\subsubsection{Summary of Recommendations}

A full discussion of the recommendations generated by this study can be found in Section 5 of this report. Table 1.1 summarizes the key suggestions to improve the accessibility of household transportation surveys to low-income communities, communities of color, and immigrant groups.

\section{Table 1.1: Recommendations for Enhancing Transportation Survey Methods}

\begin{tabular}{|c|c|}
\hline $\begin{array}{l}\text { Increase } \\
\text { Transparency }\end{array}$ & $\begin{array}{l}\text { Increase opportunities for community members to ask questions about the survey. Clarify } \\
\text { the purpose of the data collection efforts and the intended use of the data. }\end{array}$ \\
\hline $\begin{array}{l}\text { Protect Data and } \\
\text { Privacy }\end{array}$ & $\begin{array}{l}\text { Communicate how collected data will be stored, who will have access to that data, and } \\
\text { clarify how participants will be protected. Consider adopting more flexible approaches to } \\
\text { data collection that might be of a highly personal or identifying nature. }\end{array}$ \\
\hline $\begin{array}{l}\text { Community } \\
\text { Engagement }\end{array}$ & $\begin{array}{l}\text { A lack of diverse participation in survey research can be partially remedied by collaborating } \\
\text { directly with community organizations to help reach the populations they serve. Consider } \\
\text { how focus group or other communal settings may allow participants to more accurately } \\
\text { complete surveys (as they would have opportunities to ask for help, ask questions, and } \\
\text { otherwise feel more comfortable completing surveys). Contracting or otherwise directly } \\
\text { compensating community organizations for their expertise will yield higher rates of survey } \\
\text { completion amongst many groups, particularly those who are most vulnerable. }\end{array}$ \\
\hline Language Use & $\begin{array}{l}\text { Surveys must be translated into a variety of languages that reflect the city's population. } \\
\text { However, translation is not enough; efforts must be made to engage immigrant communities } \\
\text { and communities of color in order to ensure that the way that survey questions and } \\
\text { procedures are written are culturally relevant. There may not be direct translations that work } \\
\text { for some populations, and this study also finds that the language used in the one-day travel } \\
\text { survey may be problematic for some communities of color. }\end{array}$ \\
\hline $\begin{array}{l}\text { Seek Out } \\
\text { Alternatives to } \\
\text { One-Day Travel } \\
\text { Diary }\end{array}$ & $\begin{array}{l}\text { Participants in this study reported that a one-day snapshot of their travel behaviors would } \\
\text { never fully capture the transportation behaviors of the populations included in this research. } \\
\text { Thus, efforts should be made to consider multiday studies while also considering how } \\
\text { certain kinds of technology with higher rates of accuracy in measuring mobility might be } \\
\text { used (e.g., GPS technologies). However, GPS technologies are not a perfect solution as } \\
\text { many immigrants and people of color in this study reported that they would be unlikely to } \\
\text { share their GPS data for the purposes of a research study. }\end{array}$ \\
\hline
\end{tabular}




\subsection{DATA AND METHODS}

\subsection{RESEARCH APPROACH}

This project took a mixed-methods approach to exploring the dual questions of 1) how well existing OHAS data represents marginalized groups; and 2) how limitations of current survey methods might be enhanced in order to increase survey completion from more vulnerable groups. We described our research methods in detail below.

\subsection{QUANTITATIVE ANALYSES}

\subsubsection{Sources and Sample}

The Oregon Department of Transportation (ODOT) commissioned the OHAS and contracted with external survey professionals to develop and implement it. The contractors deployed a stratified random sample protocol throughout the 10 Oregon regions at various points from 2008 to 2011, using a combination of addressed-based and landline and cell phone random digit dial frames (Bricka, 2018; NuStats, 2010). In so doing, they aimed to derive representative proportional samples throughout the regions and oversampled "hard-to-reach demographic groups including low-income, Hispanics, African-Americans, large households and young households” (NuStats, 2010:5). As discussed further below, sampling stratum were defined by household size and employment status with post-survey sample weights calculated based on socioeconomic and geographic factors throughout the regions (NuStats, 2010).

The full OHAS dataset estimates daily household travel behavior for 17,941 households (and their members) during the study period from each region (Bricka, 2018). Participating households kept a one-day travel diary, and completed travel logs were collected via mail or telephone . Our analytical sample includes 6,107 OHAS household respondents in the fourcounty Portland metropolitan area. They completed their one-day travel diaries on weekdays in April and May 2011. We used GIS to locate the 6,107 households in 2010 census tract boundaries, which we use in our analysis of neighborhood-level racial representation in this study.

Figure 1.1 displays the 457 census tracts that contained an OHAS household respondent in the four-county Portland metropolitan study area. Our sample included responses for 4,513 households across the majority of tracts $(\mathrm{N}=353$ of 355) in the three-county ODOT Region 1/Metro planning area (i.e., Clackamas, Multnomah, and Washington counties). Our sample also included responses for 1,594 households in all of the tracts $(\mathrm{N}=104)$ of Clark County, WA, which is in the Southwest Washington Regional Transportation Commission MPO transportation planning area. Despite some missing cases that do not appear to be related to coding errors from the data source - but rather to an omission of data from the source itself - our 
initial sample (i.e., 6,107 households) closely matches the sample of 6,108 households studied in previous research (Clifton et al., 2016a, 2016b).

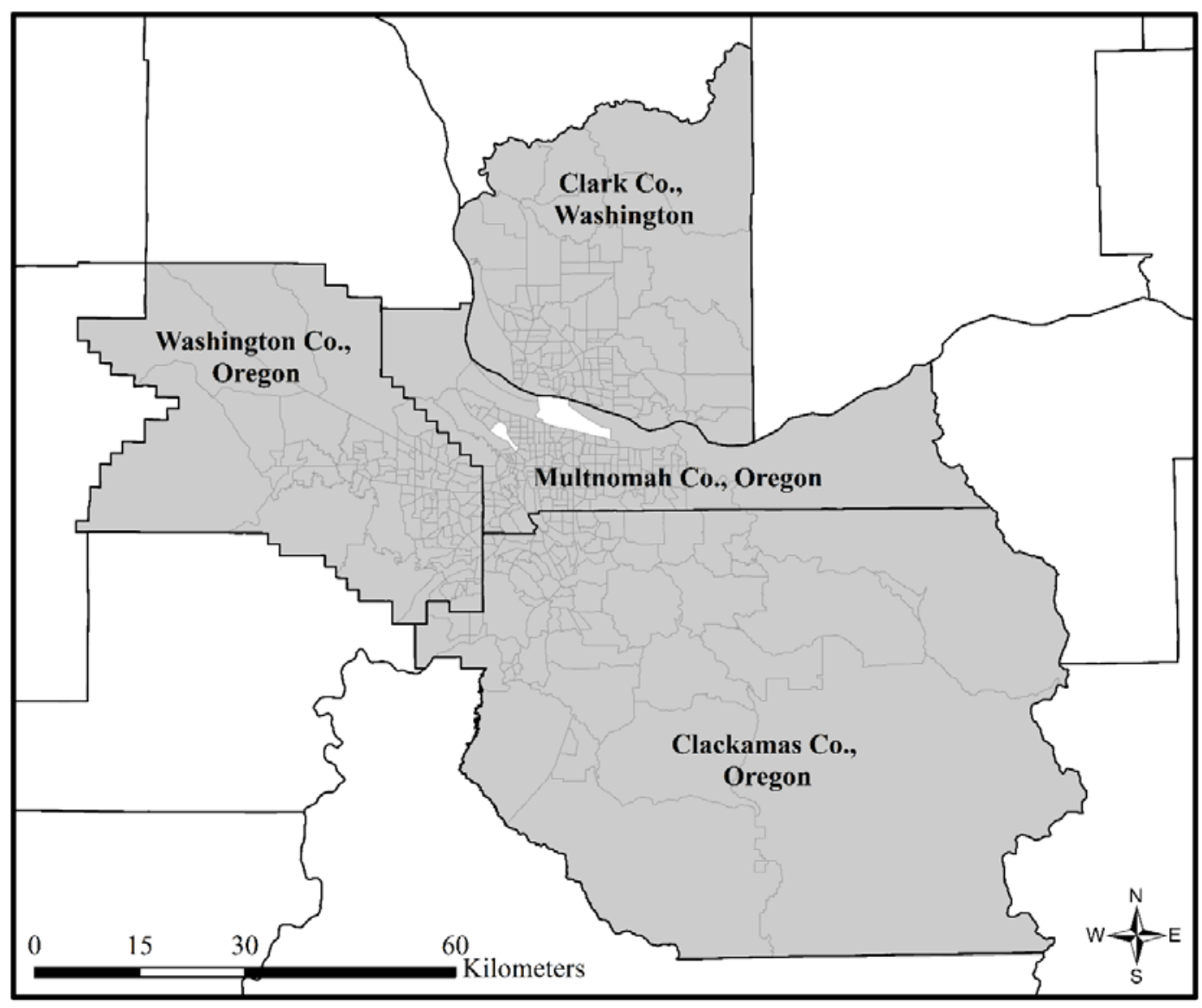

Legend

County Boundaries

Census Tracts with Household Respondent to 2011 OHAS (N=457)

Figure 1.1. County and Tract Boundaries in the Portland Metropolitan Study Area.

\subsubsection{Assessing Racial Representation in the 2011 OHAS}

To assess racial representation in the 2011 OHAS, we compared aggregate- and tract-level householder racial identification across the 2010 Decennial Census (Manson et al., 2017) and unweighted and weighted 2011 OHAS samples. The 2011 OHAS included a question about the householder's racial identity that solicited responses similar to those obtained by the 2010 Decennial Census question regarding the householder's racial identity by non-Latinx and Latinx status. We use the gender-neutral term "Latinx" (Barcelos, 2018) instead of "Hispanic" or the gendered term "Latino," which were used in the census and in the OHAS. To assess racial representativeness, we developed six comparable measures of household racial identification between the 2011 OHAS and the 2010 Decennial Census given similarities across the two datasets. The first is the percentage of Latinx householders. For brevity, we drop the "NonLatinx" status from the other householder racial identifiers and call these remaining measures the 
percentage of householders that identify as White, Black, Indigenous (i.e., American Indian/Alaska Native), Asian, or Pacific Islander (PI)/Other/Multiracial. We used the number of 2011 OHAS household respondents as the denominator for the OHAS household racial identification variables at the aggregate and tract levels. We used the number of total households from the 2010 Decennial Census as the denominator for the census household racial identification variables at the aggregate and tract levels.

Despite the sparse amount of publicly available information about the OHAS methodology, we were able to discern that weighted sample estimates in the OHAS could be calculated using the following assumptions and parameters. The OHAS used socioeconomic characteristics of populations to construct stratified sampling frames and post-survey weighting procedures to align the samples with the 2000 Decennial Census and the 2007 (one-year) and 2006-2008 (three-year average) population estimates in the American Community Survey (ACS) (NuStats, 2010). The OHAS data contain a "household weight" , which is a standard "base weight" that is "the inverse probably of selection for each sample members" (Dillman et al., 2014:87). The OHAS also includes a "final household weight" (NuStats, 2010) or "household expansion factor," as it is called in our dataset.

We did not have technical documentation about the calculation of the household expansion factor for the 2011 OHAS in the Portland metropolitan area. However, given the preference for common OHAS protocols throughout the ODOT regions, we assume it may have been calculated similarly to that for ODOT Region 2. In that region, the household expansion factor is a product of the household weight and adjustments for multiple cell phone numbers and householdranking adjustments that, when summed, would equal the known population totals for household size, household income, workers in a household, and county of residence . NuStats (2010:14) contains additional technical details on how the household ranking adjustments included imputation for missing values.

We calculated the 2011 OHAS weighted sample estimates of household racial identification by applying the household expansion factors to unweighted samples of each householder's racial identification in the OHAS data. We then summed the weighted estimates of householders by their racial identification for all householders included in the 457 tracts that had an OHAS household respondent. We compared those weighted estimates to the unweighted estimates from the 2011 OHAS and the 100 percent counts from the 2010 Decennial Census. In so doing, we anticipated that the OHAS estimates would not match the 2010 census counts because the OHAS used earlier census and American Community Survey data to calibrate the sample estimates, and it primarily considered socioeconomic and geographic factors in constructing the weights.

\subsubsection{Assessing the Relationship Between the 2011 OHAS Household Response Rate and Householder Racial Identity}

We estimated the percentage of household respondents to the 2011 OHAS using the following procedures. After locating the OHAS household respondents, we divided the number of household respondents in a tract by the total number of (occupied) households in the tract from the 2010 U.S. Decennial Census and turned the resulting ratio into a percent variable. We visualized the spatial distribution of the 2011 OHAS household response rates across our study 
area. We also assessed the bivariate association between the 2011 OHAS household response rate and householder racial identity at the tract level using a Kendall Tau-b correlation coefficient that accounts for non-normally distributed data (Downey, 2006).

\subsubsection{Identifying Sites for Focus Group Research}

We used the 2011 OHAS and 2010 Decennial Census data to characterize the sites we targeted for focus group research. We targeted tracts that had low OHAS household response rates and high Nonwhite racial composition for in-depth qualitative research, summarized in detail in the latter half of this report.

\subsection{QUALITATIVE ANALYSES}

\subsubsection{Focus Group Process}

During the course of each focus group, a variety of data were collected. Each focus group began when a participant completed a consent form and filled out a demographic questionnaire that collected anonymous information about variables such as gender, race, age, and educational background. Some individuals elected not to complete this questionnaire, and therefore, we were only able to provide partial demographic data on focus group participants. See Table 2.2.

Once participants completed the demographic questionnaire, the first part of the focus group began. Led by a single facilitator, participants were asked questions about their familiarity with taking surveys, as well as their general transportation behaviors. Participants were then asked to complete a brief activity in which they were asked to recall a typical week in their life, and characterize the types of trips they took during a normal week. They were then asked to map these trips on a large calendar in order to inspire a conversation about travel and mobility patterns. Although this activity was not meant to generate rigorous data for analytical purposes, it did allow the focus group participants and the research team to quickly observe general trends in transportation behaviors across a one-week time period and allowed participants to think about their mobility patterns.

Following this activity, participants were given a copy of the OHAS one-day travel diary and given time to read through it. A structured discussion then asked participants to consider 1) if they would complete a survey like this; 2) what challenges they might have in completing a travel diary; 3) what an appropriate incentive to complete the survey would look like; and 4) to reflect on the week-long exercise and discuss the extent to which a one-day travel diary would capture their travel behaviors accurately.

A final series of questions asked participants about any concerns they had about using GPS technologies to capture their travel behaviors, and asked them to reflect on any other ideas or suggestions they had about transportation surveys. 


\subsubsection{Focus Group Participant Recruitment}

Focus groups were held in neighborhoods that were found, in the quantitative analysis portion of this project, to be underrepresented in the OHAS survey. Efforts were made to partner with local organizations in order to generate interest and participation from specific populations (lowerincome, immigrant, and transit-dependent populations). A total of six focus groups were hosted, with 57 participants. Partnerships with local organizations meant that emails, phone calls, and paper fliers were all utilized for recruitment purposes. Additionally, in-person outreach was conducted on multiple days leading up to each focus group. Participants were offered dinner, child care, translation services, a public transit day pass, and $\$ 25$ to a local grocery store for their participation.

Table 2.1: Focus Group Locations and Participants

\begin{tabular}{l|c}
\hline Location & Participants \\
\hline Beaverton & 12 \\
Rockwood Spanish & 8 \\
Rockwood English & 5 \\
East Portland, Various Languages & 11 \\
Africa House Staff & 14 \\
People, Places, Things Facilitators & 7 \\
\hline & Total: $\mathbf{5 7}$ \\
\hline
\end{tabular}

Beaverton (1 group): Our first focus group was held at the Beaverton public library and participants in that group were recruited via fliers at public housing complexes, through announcements and emails from staff at affordable housing complexes, and through word of mouth from interested participants. City of Beaverton staff working on affordable housing were also asked to send emails to potentially interested participants.

Rockwood (2 groups): In the Rockwood neighborhood of East Portland, participants for two focus groups were recruited in Spanish and in English at the Rosewood Initiative community center. The two focus groups were held concurrently at the Rockwood Public Library.

East Portland (1 group): The Immigrant and Refugee Community Organization's (IRCO) Africa House hosted a focus group for African immigrants. However, due to a large variety of linguistic needs and language barriers, this focus group does not have complete demographic data. The majority of participants in this group were young women from a variety of African nations.

Staff of Local Organizations (2 groups): In the first group, staff from IRCO's Africa House were asked to participate in a focus group that more narrowly focused on assessing the OHAS one-day travel diary, and the challenges that immigrant and non-native, English-speaking populations might face.

In the second group facilitators from the English as a Second Language (ESL) educational organization, People, Places, Things, were asked to reflect on a series of in-class exercises that they conducted with ESL learners that related to transportation surveys. In a series of classes the organization held over the course of two months, they tested a variety of simplified travel surveys written in English with ESL class participants in order to better understand how nonnative English speakers might respond to a travel survey in English. A total of 112 ESL learners 
participated in the classes that informed the ESL staff focus group’s discussion.

\subsubsection{Focus Group Sample}

In order to participate in a focus group, participants had to be at least 18 years of age and live in the greater Portland metropolitan area. Efforts were made to provide translation in a variety of languages in order to include as diverse a sample as possible. When presenting data below, we provided the location of the focus group a participant attended and offered some additional demographic information about that person when possible. It is relevant to note that, on average, participants in these focus groups are less economically advantaged than the average Portland resident and, on the whole, this sample is more racially and ethnically diverse than the general Portland population (2010 Census data shows Portland to be 77 percent White; 9 percent Hispanic/Latino; 8 percent Asian; 6 percent Black; with average household earnings of \$38,638). The relative diversity of this sample is due in part to the fact that the areas where we found lower rates of survey completion tended to be lower income and more racially diverse, but is also due to active recruitment of focus group participants through community organizations that serve communities of color and lower-income populations.

Table 2.2: Focus Group Demographics

\begin{tabular}{c|c|c|c|c}
\hline \multicolumn{1}{c}{$\begin{array}{c}\text { Gender } \\
(\mathbf{n = 5 7 )}\end{array}$} & $\begin{array}{c}\text { Age } \\
(\mathbf{n}=50)\end{array}$ & $\begin{array}{c}\text { Race/Ethnicity } \\
(\mathbf{n}=50)\end{array}$ & $\begin{array}{c}\text { Annual Income } \\
(\mathbf{n}=50)\end{array}$ & $\begin{array}{c}\text { Primary Language } \\
(\mathbf{n}=50)\end{array}$ \\
\hline Men (17) & $18-24(5)$ & Black/African American (20) & Less than \$5,000 (16) & English (20) \\
Women (38) & $25-34(10)$ & Hispanic/Latinx (8) & $\$ 5,000-\$ 15,000(3)$ & Spanish (8) \\
No answer (2) & $35-44(14)$ & White (11) & $\$ 15,000-\$ 24,999(8)$ & French (2) \\
& $45-54(9)$ & Other (9) & $\$ 25,000-\$ 34,999(5)$ & Swahili (5) \\
& $55-64(6)$ & No answer (2) & $\$ 35,000-\$ 44,999(3)$ & Somali (4) \\
& $64+(5)$ & & $\$ 45,000-\$ 54,999(3)$ & Arabic (4) \\
& No answer & & $\$ 55,000+(3)$ & Temene/Krio (1) \\
& $(1)$ & & No answer (9) & No answer (6) \\
\hline
\end{tabular}

*Note: not all participants $(n=57)$ completed all demographic questions and not all demographic questions asked are presented in this table. This table is meant to offer a snapshot of the focus group sample despite there being some missing data.

\subsubsection{Qualitative Data Analysis Procedures}

Focus groups were audio recorded and transcribed. Transcripts were then analyzed using a multistep process of constant comparison (Glaser and Strauss, 1967; Strauss and Corbin, 1999). In this case, members of the research team each read the focus group transcript two times and met to discuss the consistent patterns across multiple interviews. Throughout this group discussion, transcripts were referred back to and categories were merged, refined, or deleted as agreed upon as a group.

Final conceptual coding categories included "barriers to survey completion, motivations to complete surveys, suggestions to improve surveys, limitations of travel diary, and GPS 
technology use.” Each of these larger "parent” codes had subsets of smaller "child” codes underneath them. For example, the "barriers to survey completion" code included child codes of "language, distrust of government, lack of incentive, privacy, racism, time, too hard". All parent codes included some child codes to help identify patterns in the data. In total, we had 27 parent and child codes.

Once finalized, this coding scheme was used within the Dedoose qualitative data analysis program, which allows textual data from the transcripts to be sorted into the above-noted codes and to see how consistently patterns and themes emerge across qualitative data. All transcripts were read a final time and relevant segments of the focus group data were coded into the categories noted. This allowed the researchers to observe trends in the data and confirm the consistency of the findings across multiple focus groups.

\subsubsection{Additional Data Collection: English as a Second Language Community Partnership}

In order to generate additional findings on the challenges that immigrant groups and those who speak English as a second language face, the research team partnered with the Portland-based organization People, Places, Things (PPT). PPT offers free English classes to anyone wanting to learn. Their classes are offered in multiple locations across the city (including schools and public libraries) and the classes convene multiple language groups in one place.

Our partnership with PPT was intended to allow for data collection to take place amongst groups who did not speak English as their primary language and who might be unlikely to take a household transportation survey due to language barriers. At the suggestion of PPT, we devised a unique multisite approach to assessing transportation survey methods amongst non-native English speakers. We began the process by taking existing transportation survey models, including the OHAS survey, and working to generate alternative versions of the surveys that were in very basic English. Our goal in this process was to maintain the general concepts in the surveys while making the language more accessible to a very wide multilingual audience. This process resulted in three simplified surveys, which varied in their approach to asking questions. One survey predominately featured images and very simple questions; a second survey was a very simplified travel diary; and a third was a lengthier and more complex survey that was administered online.

Data Collection: During the fall of 2018, the three survey models were tested in seven different free ESL classes. The classes were held in different locations and at different times of day. Participants' primary languages included Spanish, Russian, and Mandarin. Classes ranged from three students per class during one daytime class to more than 20 in an evening class. A total of 112 ESL learners completed surveys; some students completed all three surveys, while some students completed only one. However, as our intention was not to compare the three surveys but to see what aspects of each survey worked amongst this population as a whole, we do not see this as a problem.

A member of the research team was present when the survey models were tested, though each class was facilitated by a team of trained ESL teachers, at least one of whom was given specific 
instructions regarding how to administer the model survey. In this way, class would flow normally, and the class facilitators planned how to make the survey completion a learning opportunity. Class facilitators were also asked to record specific observations regarding the surveys which they either recorded in writing, or provided orally to a research team member at the end of class (e.g., What questions or phrases did ESL learners struggle with? What questions did ESL learners ask when completing the survey?). Research team members who attended the classes also recorded written observations.

Resulting Data: The data that resulted from this effort is somewhat unique, with more than 100 surveys completed by individual learners and a series of facilitator and research team observations. From the surveys, we were able to glean information about the types of questions that respondents might leave blank, while the observational data allowed the research team to generate a series of suggestions for enhancing transportation survey completion amongst those with limited English proficiency. In order to ensure the validity of the observations made by class facilitators and research team members, one 90-minute focus group was convened with seven class facilitators. This focus group allowed the research team to present preliminary findings from the survey models and the written observations and then asked the class facilitators to confirm, add to, or clarify their thoughts on how to increase survey accessibility for non-native English speakers.

Limitations: The goal of this process was not to compare the three survey approaches we developed, nor was the goal to perfectly replicate a simplified version of the OHAS survey. Rather, the goal of survey testing was to see which approaches and which styles of questions were most likely to elicit responses and reduce confusion from ESL learners. These findings are not generalizable, nor are they intended to offer anything more than suggestions for how to include a wide sample of those with limited English proficiency in instances where surveys are not translated into multiple languages. Future research must engage multiple language populations directly, in their preferred language, in order to confirm and extend the findings we offer in this report. We recognize the inherent limitations of our current findings as they do not feature the direct feedback of multiple language groups. However, given the financial and temporal constraints of this project, we believe that the findings presented in this report offer a useful place from which to develop additional findings and research on enhancing survey access and completion amongst non-native English speakers. 


\subsection{QUANTITATIVE FINDINGS}

\subsection{RACIAL REPRESENTATION IN THE 2011 OHAS}

The majority of the 6,107 OHAS householder respondents included in our sample identified as White ( $\mathrm{N}=5,559 ; 91.03$ percent). The remaining householder respondents identified as Latinx (i.e., Hispanic) $(\mathrm{N}=152,2.49$ percent), Asian ( $\mathrm{N}=116,1.90$ percent), Black (or African American) (N=60, 0.98 percent), or Indigenous (i.e., American Indian or Alaska Native) (N=37, 0.61 percent). Another 63 (1.03 percent) of the householders identified as "Other," which was primarily specified as "Multiracial” or "Mixed," different combinations of racial identities, the U.S. census racial category of Pacific Islander, and a variety of other single identities not typically included in the U.S. census general racial classification system. Notably, 120 (1.96 percent) of householders refused to provide their racial identity.

When compared to the 2010 Decennial Census, the 2011 OHAS consistently overrepresented White and underrepresented Nonwhite householders in the four-county Portland metropolitan study area. As seen in Figure 3.1, the aggregated 2011 OHAS unweighted and weighted percentage of White householders exceeded the percentage of White householders in the 2010 census by 8.8 and 8 percentage points, respectively. The 2011 OHAS achieved greater aggregate-level representation for Indigenous householders. However, it consistently underrepresented all other Nonwhite householders, especially Latinx and Asian householders.

Figure 3.2 compares the tract-level mean householder racial identification across the 2010 Decennial Census and the 2011 OHAS unweighted and weighted sample estimates. These tractlevel patterns are generally consistent with the aggregate-level findings summarized in Figure 3.1. That is, on average across 457 census tracts, the OHAS represented Indigenous householders, underrepresented other Nonwhite householders, particularly Latinx and Asian householders, and overrepresented White householders. 


\begin{tabular}{|c|c|c|}
\hline \multirow{3}{*}{$\%$ Latinx } & 2010 Census & 6.9 \\
\hline & 2011 OHAS Unweighted & 2.5 \\
\hline & 2011 OHAS Weighted & 2.7 \\
\hline \multirow{3}{*}{ \% White } & 2010 Census & 82.2 \\
\hline & 2011 OHAS Unweighted & $\begin{array}{lll}\square & 91.0\end{array}$ \\
\hline & 2011 OHAS Weighted & 90.2 \\
\hline \multirow{3}{*}{$\%$ Black } & 2010 Census & $\mathbf{\square} 2.8$ \\
\hline & 2011 OHAS Unweighted & 1.0 \\
\hline & 2011 OHAS Weighted & 1.2 \\
\hline \multirow{3}{*}{$\%$ Indigenous } & 2010 Census & 10.6 \\
\hline & 2011 OHAS Unweighted & 0.6 \\
\hline & 2011 OHAS Weighted & 0.8 \\
\hline \multirow{3}{*}{$\%$ Asian } & 2010 Census & 4.9 \\
\hline & 2011 OHAS Unweighted & 1.9 \\
\hline & 2011 OHAS Weighted & 2.0 \\
\hline \multirow{3}{*}{$\begin{array}{l}\% \text { Pacific } \\
\text { Islander, Other, } \\
\text { Multiracial }\end{array}$} & 2010 Census & $\mathbf{\square} 2.5$ \\
\hline & 2011 OHAS Unweighted & 1.0 \\
\hline & 2011 OHAS Weighted & 1.1 \\
\hline
\end{tabular}

Aggregate Percent of Households

Figure 3.1. Aggregate Percent of Households by Householder Racial Identification in the 2010 Census and 2011 Oregon Household Activity Survey (OHAS) in 457 Census Tracts Within the Four-County Portland Metropolitan Study Area. 


\begin{tabular}{|c|c|c|}
\hline \multirow{3}{*}{$\%$ Latinx } & 2010 Census & m 6.8 \\
\hline & 2011 OHAS Unweighted & 2.8 \\
\hline & 2011 OHAS Weighted & 2.8 \\
\hline \multirow{3}{*}{$\%$ White } & 2010 Census & 82.7 \\
\hline & 2011 OHAS Unweighted & 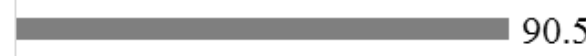 \\
\hline & 2011 OHAS W eighted & 90.0 \\
\hline \multirow{3}{*}{$\%$ Black } & 2010 Census & 】 2.8 \\
\hline & 2011 OHAS Unweighted & 1.1 \\
\hline & 2011 OHAS Weighted & 1.2 \\
\hline \multirow{3}{*}{$\%$ Indigenous } & 2010 Census & 10.6 \\
\hline & 2011 OHAS Unweighted & 0.7 \\
\hline & 2011 OHAS Weighted & 0.9 \\
\hline \multirow{3}{*}{$\%$ Asian } & 2010 Census & $\mathbf{\square} 4.5$ \\
\hline & 2011 OHAS Unweighted & 1.8 \\
\hline & 2011 OHAS Weighted & 1.9 \\
\hline \multirow{3}{*}{$\begin{array}{l}\text { \% Pacific } \\
\text { Islander, Other, } \\
\text { Multiracial }\end{array}$} & 2010 Census & 2.5 \\
\hline & 2011 OHAS Unweighted & 1.3 \\
\hline & 2011 OHAS Weighted & 1.2 \\
\hline
\end{tabular}

Average Percent of Households

Figure 3.2. Tract-Level Average Percent of Households by Householder Racial Identification in the 2010 Census and 2011 Oregon Household Activity Survey (OHAS) in 457 Census Tracts Within the Four-County Portland Metropolitan Study Area.

\subsection{OHAS HOUSEHOLD RESPONSE RATE AND BIVARIATE CORRELATIONS}

Figure 3.3 displays the spatial distribution of the quartiles of the 2011 OHAS household response rate. It shows that around 75 percent of the 457 tracts included in this portion of the analysis had an OHAS household response rate below the statewide and Portland region response rate of 1 percent (Bricka, 2018; Geller, 2013). Figure 3.3 also shows that the upper quartile of the OHAS household response rate is spatially distributed through the urban core and periphery of the Portland metropolis, which are receiving considerable investments in transportation infrastructure and becoming more upper class and White (McKenzie, 2013). The bivariate correlations summarized below elaborate the racial context of these spatially varying household response rates in the Portland metropolitan study area. 


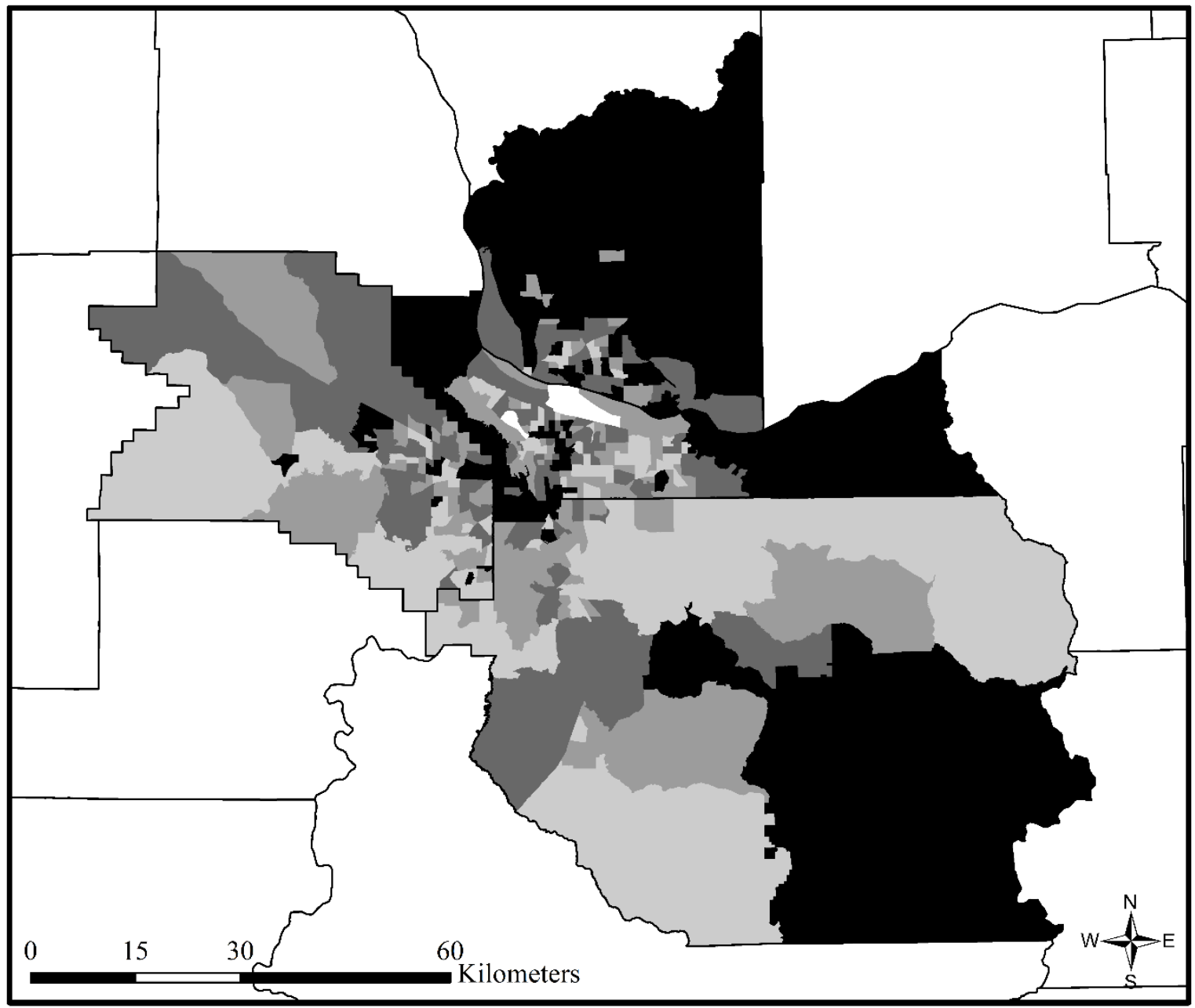

Legend

County Boundaries

Tract-Level Percent of 2011 OHAS Household Respondents

Quartile Ranges

25th Percentile: .10 to $.51 \%$

25th to 50 th Percentile: $>.51$ to $.72 \%$

50th to 75 th Percentile: $>.72$ to $.97 \%$

$>75$ th Percentile: $>.97$ to $2.78 \%$

Figure 3.3. Quartiles of Tract-Level Percent of Households that Responded to the 2011 Oregon Household Activity Survey (OHAS) in the Four-County Portland Metropolitan Study Area. 
Table 3.1 presents the tract-level bivariate correlations between the 2011 OHAS household response rate and household racial identification from the 2010 Decennial Census. There are two clear patterns evident in the table. First, the OHAS household response rates are positively associated with the percentage of White householders and negatively correlated with all indicators of Nonwhite households. The strongest negative correlation occurred between the percentage of Latinx householders and the OHAS household response rate. These associations should be expected given the extent of racial misrepresentation in the OHAS that was reviewed above. Further, the percentages for most Nonwhite householders are positively correlated with each other (except for the percentages of Indigenous and Asian householders), and all percentages of Nonwhite householders are negatively correlated with the percentage of White householders.

Table 3.1. Kendall Tau-b Correlation Coefficients for the Associations Between the 2011 OHAS Household Response Rate and 2010 Decennial Census Householder Racial Identification

\begin{tabular}{|c|c|c|c|c|c|c|}
\hline & 1 & 2 & 3 & 4 & 5 & 6 \\
\hline \multicolumn{7}{|l|}{$\begin{array}{l}\text { 1. Percent of OHAS household } \\
\text { respondents, 2010-2011 }\end{array}$} \\
\hline 2. Percent Latinx householder, 2010 & $-0.281^{* * *}$ & & & & & \\
\hline 3. Percent White householder, 2010 & $0.258 * * *$ & $-.594 * * *$ & & & & \\
\hline 4. Percent Black householder, 2010 & $-0.075^{*}$ & $.340 * * *$ & $-.573 * * *$ & & & \\
\hline 5. Percent Indigenous householder, 2010 & $-0.129 * * *$ & $.253^{* * *}$ & $-.170 * * *$ & $.198 * * *$ & & \\
\hline 6. Percent Asian householder, 2010 & $-0.122 * * *$ & $.186^{* * *}$ & $-.466 * * *$ & $.347 * * *$ & $-.075 *$ & \\
\hline $\begin{array}{l}\text { 7. Percent Pacific Islander, Other, or } \\
\text { Multiracial householder, } 2010\end{array}$ & $-0.115^{* * *}$ & $.370 * * *$ & $-.486 * * *$ & $.537 * * *$ & $.218^{* * *}$ & $.262 * * *$ \\
\hline
\end{tabular}

Note: $N=457$ census tracts. ${ }^{*} p<.05 ; * * * p<.001$ (two-tailed test).

\subsection{SITES FOR FOCUS GROUP RESEARCH}

Figure 3.4 displays the three geographic locations that featured prominently in our focus group research. We contextualize these focus group locations by drawing one-kilometer buffers around the locations and providing summary statistics on the tracts that intersect those buffers. Table 3.2 summarizes those descriptive statistics. As shown in Table 3.2, all three locations were surrounded by tracts that, on average, had relatively low OHAS household response rates and high percentages of Latinx/Nonwhite householders. This racial context, and other neighborhood conditions discussed below, made these focus group locations ideal for pursuing our second research aim of this study: to engage marginalized populations in the Portland area to ascertain how best to increase survey completion amongst underrepresented groups. 


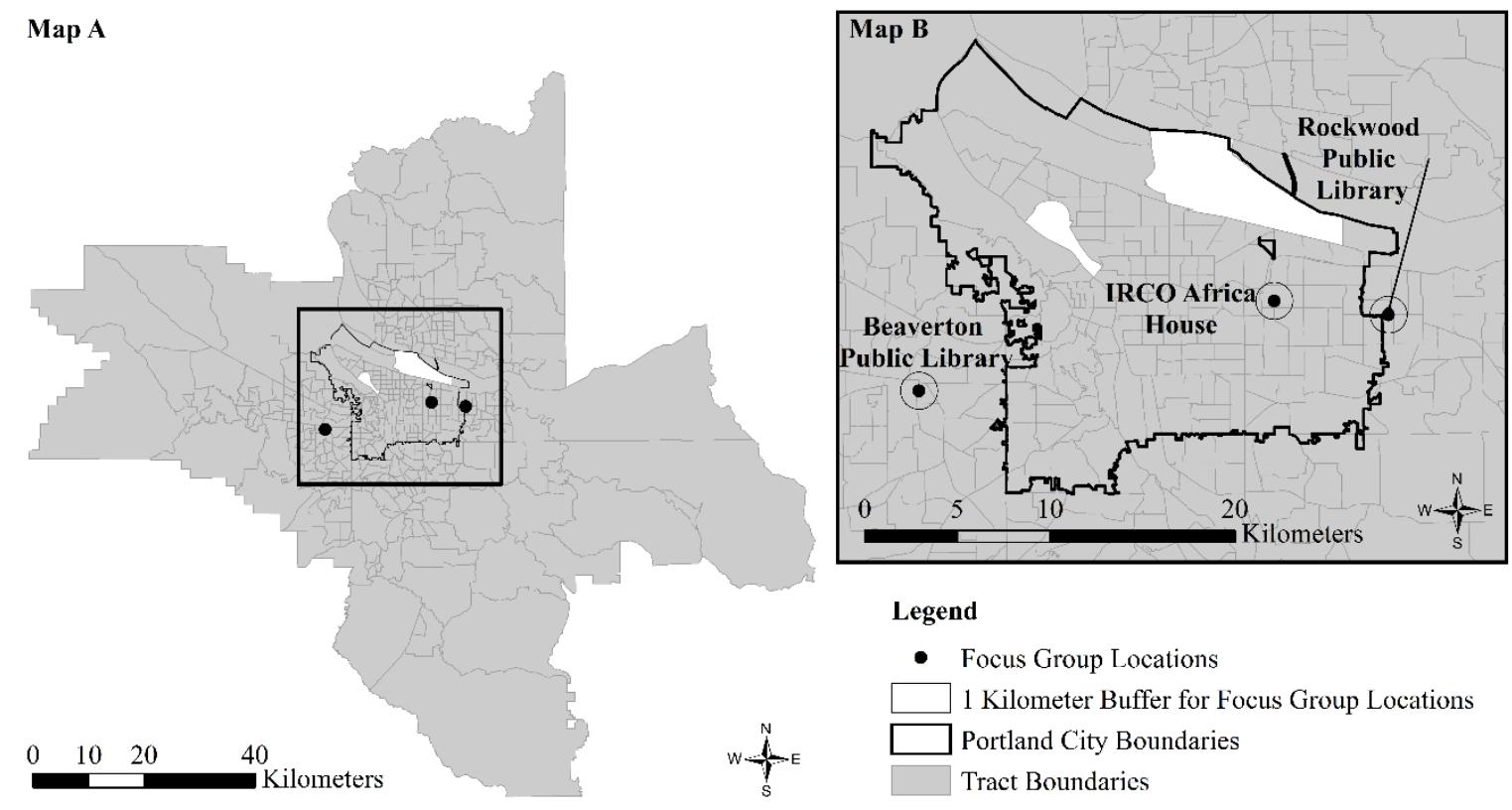

Figure 3.4. Focus Group Locations and Their One-Kilometer Buffer in Map (A) of the Four-County Portland Metropolitan Study Area and in Map (B) of Portland City and Vicinity. Note: "IRCO" in Map B refers to The Immigrant and Refugee Community Organization.

Table 3.2: Descriptive Statistics for the 2011 OHAS Household Response Rate and the 2010 Householder Latinx/Nonwhite Identification in Tracts Intersecting the One-Kilometer Buffer to Focus Group Location

\begin{tabular}{ccccccc}
\hline Focus Group Location & $\begin{array}{c}\text { N } \\
\text { Tracts }\end{array}$ & \multicolumn{1}{c}{ Variable } & Mean & SD & Min. & Max. \\
\hline Beaverton Public Library & 7 & $\begin{array}{l}\text { Percent 2011 OHAS } \\
\text { household respondents }\end{array}$ & 0.69 & 0.27 & 0.32 & 1.04 \\
\hline & 5 & $\begin{array}{l}\text { Percent Latinx/Nonwhite } \\
\text { householder, 2010 }\end{array}$ & 27.57 & 8.84 & 13.17 & 35.30 \\
\hline $\begin{array}{l}\text { Percent 2011 OHAS } \\
\text { household respondents }\end{array}$ & 0.36 & 0.09 & 0.22 & 0.49 \\
\hline $\begin{array}{l}\text { Percent Latinx/Nonwhite } \\
\text { householder, 2010 }\end{array}$ & 35.86 & 5.02 & 28.27 & 40.61 \\
\hline $\begin{array}{c}\text { The Immigrant and Refugee } \\
\text { Community Organization's (IRCO) } \\
\text { Africa House }\end{array}$ & 8 & $\begin{array}{l}\text { Percent 2011 OHAS } \\
\text { household respondents }\end{array}$ & 0.64 & 0.23 & 0.28 & 0.88 \\
\hline $\begin{array}{c}\text { Percent Latinx/Nonwhite } \\
\text { householder, 2010 }\end{array}$ & 25.41 & 3.09 & 20.64 & 28.82 \\
\hline
\end{tabular}




\subsection{QUALITATIVE FINDINGS}

\subsection{LIMITATIONS OF ONE-DAY TRAVEL DIARY}

The focus groups convened were intended to: 1) engage individuals in neighborhoods in which OHAS survey completion rates were lower than expected in 2009-2011; 2) assess the travel diary tool used in the 2009-2011 OHAS data collection effort; and 3) collect information on other challenges to household transportation survey research amongst the relevant groups.

\subsection{BARRIERS TO ONE-DAY TRAVEL DIARY COMPLETION}

The findings presented here demonstrate that marginalized groups (in this case, immigrants and those who do not speak English as their first language, people of color, and low-income individuals) face significant barriers to completing household transportation surveys. Language barriers, time constraints, concerns about personal privacy, mistrust of the government, and issues with the construction of the survey questions themselves were all found to be significant issues across all of our focus groups.

As noted above, focus group participants were given a copy of the 2009-2011 OHAS travel diary and asked to review the diary's contents and reflect on it as a group. Participants were asked if they would complete the survey, what might make it harder for them to complete it, and what might incentivize them to complete it.

\subsubsection{Privacy Concerns as a Barrier}

The most common concern across all five focus groups was protecting participants' privacy. Participants often balked at questions on the diary like "Where were you at 3 a.m.?" and "What is the make and model of your car?” Some participants expressed feeling surveilled, others just didn't understand why a transportation survey needed this level of detailed personal information. One participant noted,

Yeah, it's a lot of information. I don't exactly quite understand, like I see like it says "Travel and Activity Survey" but it's just like when you see that and then you open it and it's just a lot of information that you have to fill out ...like for example the type of car that you drive, the year, the make, the model like why does that matter? (Beaverton)

Many other participants agreed that questions asked for details that seem irrelevant to the overall goal of the transportation survey:

Well they want everything so specific here, plate numbers? I mean they are asking for the make of the car, 'If you travelled by car, which make and model is your car?' I wouldn't give my information like that. (Spanish Rockwood) 
Some participants discussed omitting private information like their full name and the make/model of their car, and instead suggested they would prefer to submit an incomplete travel diary. Without more detailed explanation of the ways in which their personal information would be used and the importance of collecting it, participants were not comfortable providing details about their lives they found to be too private to share. As one person of color noted:

...that 3 a.m. question, that's invasive. My home address on a form that I don't know how many people are going to see is invasive. I'm not giving you the make and model of my car. I mean, if I was filling out this survey and I had to do it, for city I'd put "Portland” cross street I'd put "Flavel” that's all I'd put, and I don't think I'd even give my last name if I was asked to do that. But like over here for make and model, I'd write in "N/A" or decline to answer. (Africa House)

Additionally, participants consistently reported that they would be more likely to complete a travel diary if it were anonymous:

I would also strike out the name, like the surveys they sent me for the doctor it doesn't ask for my name, it says it's anonymous, [...] so this one I don't feel comfortable filling it out because they ask my name, and so many details. (Spanish Rockwood)

Anonymity emerged as a key concern in every focus group, demonstrating the concern participants have with providing detailed information about their travel patterns when it is linked to their name and address. While participants may not understand the need to provide the make and model of their car, it appeared they'd be more comfortable doing so anonymously.

\subsubsection{Time Investment as a Barrier}

The time required to complete a survey and travel diary came up in every focus group; participants discussed the length of the travel diary itself and the time commitment it would take to complete, describing it as too long, too much work, and too much to read. When asked about her first impression of the survey, one participant said, "The first thing you would say is 'All of this? No, I don't have time, it's too much'” (Spanish Rockwood). This initial reaction to the travel diary was common among most of the participants in every focus group, suggesting that upon receiving the survey in the mail potential respondents may be too overwhelmed by the design to even consider participating.

Another focus group participant explained how difficult it would be to fill out the survey because she doesn't know the exact address for all of the places she travels in a day; she would have to spend a great deal of additional time looking up each address on her phone before filling in the details on the travel diary:

I go to my doctors; I go to physical therapy at least once a week sometimes twice a week and I honestly couldn't tell you their address. I know exactly where they are and all the landmarks around it, but zip code? I wouldn't know, that's not information I have, I'd have to look it up. (English Rockwood) 
This additional step makes participating in the transportation survey even more burdensome, especially to low-income participants who rely on their smartphones for internet access. These comments were not unique to this participant and a reminder that spatial interpretations of the city vary widely; how one person understands and moves through space can vary dramatically from another person. One cannot assume that individuals know the stop ID of a bus or that they know the cross streets of their doctor's office.

Another consistent finding was respondents reporting being too busy in a day to fill out every place they go. One participant explained if they were going to participate in a transportation survey like this they would rather do so online or on a smartphone app where it automatically tracked her. She explained she would not have time to fill in the address of every location she went to in a day, much less every departure and arrival time. Similarly, another participant said he could do the diary but it would have to be over multiple days, stating:

I think for me, I wouldn't do it, I wouldn't complete just on that time. It would be like a two-to-three-day process, ya know? Because I've got other things to do, or they [gesturing to other participants] have things to do. You've got kids, you've got other priorities. So, I don't think it'd get done that same day. (Beaverton)

This indicated that participants would not be able to participate in the transportation study the way it was designed - namely to capture one day of travel. If respondents fill out the diary over multiple days, it would not accurately reflect their travel patterns, potentially misrepresenting their data and thus the transportation infrastructure projections that Oregon Department of Transportation makes based off these data.

\subsubsection{Discrimination and Racism as Barriers to Survey Completion}

Although participants were not specifically asked about discriminatory or racially problematic elements of the survey, consistent findings emerged in both focus groups made up entirely of people of color. Some participants expressed concern that the personal information collected on the travel diary would be shared with other government agencies and/or law enforcement. Immigrants, in particular, noted how the interconnected nature of law enforcement, transit agencies, and immigration services contributes to a general distrust of transit system data collection efforts:

And we know how the transportation and government is connected to law enforcement in these states. So it is, you know we do want transportation better but at the same time the law enforcement is involved so it's very scary. (Africa House)

This was especially concerning for communities of color, immigrant communities and lowincome communities due to their experiences of over-policing by local police bureaus and Immigration and Customs Enforcement (ICE). When asked if they would be willing to provide personal information on a survey like the travel diary, one participant responded:

If its information for public transportation yes, maybe, but if they might share it with other agencies then no, like the other lady said earlier... with ICE and everything, we are 
just waiting to see what happens so then no, because who would like to put themselves at risk? (Spanish Rockwood)

The lack of trust some immigrant communities have in governmental agencies may prevent survey participation when individuals are expected to divulge personally identifying information. As another participant noted, "I think it just doesn't feel confidential, maybe people would be afraid that [the government] would do something against them if they say anything is wrong” (Spanish Rockwood).

Some participants felt the language used on the travel diary was inherently deceptive. Despite the research team's explanation of the travel diary's purpose at the start of the focus group, participants noted that the detail of information the diary asked for did not seem to support the expressed purpose of data collection:

This is all rubbing me the wrong way, honestly. I wouldn't do this because if, especially with the current political climate a lot of our people don't feel safe divulging this type of information. And you're directly asking for it. The feeling I'm getting right now is, the reason you're telling me you want this survey and the way the information is coming to me doesn’t align. I feel like there’s an ulterior motive. (Africa House)

If participants do not have a full picture of the purpose for the travel diary and an explicit explanation for the need to ask respondents for detailed personal information, many are likely to refuse to give their information for fear it might be used against them. Participants explained that the questions on the travel diary made them feel like they were being surveilled, and that this level of detailed information was unnecessary to improve public transit in Portland.

Many participants of color also expressed concern regarding how questions were asked on the travel diary, noting that the questions felt similar to being profiled and interrogated by the police. The lack of transparency about who funded the transportation study and why they were interested in such detailed personal information about respondents further alienated some participants in our study and would prevent them from responding to the transportation survey.

I think this sort of put everything together that I've been trying to say, this feels retraumatizing for us; for me as someone who reads and understands English very well, reading this and trying to fill this, feels like I'm going through trauma again because a lot of, not even what's said but how it's said feels like what I hear from officers, like "WHAT IS YOUR NAME?” “WHERE YOU GOING?” “WHO'S WITH YOU?” "WHERE DO YOU LIVE?” We've heard those questions before, there’s a way that you can frame that that makes us, or whoever is filling this out feel a little bit more respected and I feel like they missed that point. (Africa House)

Similarly, another participant noted that survey respondents are asked to give private information, and as such the survey questions should be worded in way that reflects appreciation for this. One participant explained, 
If you're asking me for my information, it's a privilege if I'm giving you that information. There's not even one word for "Please tell me" you know there's no, it just feels like, you know it almost feels like you're interrogating me like a police officer talking to me when I read it. (Africa House)

Recipients of the travel survey may be disinclined to participate if they do not feel like their information will be valued and protected. Some participants explained that the level of respect reflected in the language of the survey questions should correspond with the amount of detailed personal information respondents are being asked to give.

I'm still stuck on the language of this document because it makes me feel a certain way even just looking at it right now. Like, it feels like it plays to the oppressive powers, it feels like they're talking down to us. (Africa House)

The current political climate added an additional level of skepticism for participants who are immigrants. Their concerns stemmed from the types of questions asked on the travel diary and the lack of clear explanation for the need of such information. As one of the participants in the Spanish Rockwood group explained:

They ask for too many specific l details. I think that right now with everything that is going on with ICE and all of that if someone asks you 'What time do you leave home?' 'Where do you go?' 'Where do you leave your children?' 'Where do you go to work?', I wouldn't feel comfortable writing that down. I would be wondering why do they want to know that, why do they want to know where I'm going and when? with so much detail I mean...perhaps if it didn't ask with so much detail, instead of the exact time maybe just choose between 'Morning/Noon/Afternoon/Night' instead of being so specific. The same with the question about which car you drive and all of that. I think that this is a worry for a lot of people, I mean I would be worried. (Spanish Rockwood)

When potential respondents feel their information could be used against them, they are unlikely to complete the travel diary even when the diary is translated into their preferred language. Simply translating the diary into other languages without taking into account that the questions themselves may reflect a culture of colonization is not enough. As another participant noted:

This is discrimination based on language, ethnicity and country of origin. So, if it's coming from the government they should understand that they are discriminating against people. These people are participating in the economy of the country, they are paying taxes, they are paying the fees for the transportation. (Africa House)

In an effort to get transportation data that better reflects the communities in Oregon, and more specifically the Portland metro area, the transportation survey needs to take into account the various backgrounds of the communities here and use culturally sensitive language that makes equitable participation attainable for communities of color as well as immigrant communities. 


\subsubsection{Language Barriers}

Language came up as a barrier to completing the travel diary in a number of ways. The first, and most obvious, is that the transportation survey was in 2009-2011 only translated into English and Spanish by ODOT, suggesting that there may have been many immigrants who speak other languages who could not have filled out the last iteration of the survey at all. As one participant noted, as more immigrant groups move to the area, the lack of language diversity would be highly limiting:

They're only English and Spanish, so was this survey really only intended for just targeting two populations? They have to translate to Vietnamese, Chinese and they don't speak English. We also have people that speak Swahili, Somali, you name it. (Africa House)

Participants were surprised to find that in the Portland metro area, where it is common to find government documents translated into many different languages, the 2009 OHAS travel diary appears to only have been offered in two (at present, the research team could not locate any technical documents for the last round of data collection in Portland, so it could not be confirmed that additional translation was NOT done. Additional requests for information made to Metro did not produce additional information). This immediately excludes the voices of some of the very communities who rely on public transportation the most: low-income and immigrant communities.

Focus group participants also discussed how potential survey respondents who are not highly proficient in reading or speaking English may be additionally burdened by the amount of time it would take to understand and respond to questions. As one participant noted: "I feel like it's a lot of work for people. Is there a very short way to record where you go? I feel like when you don't speak the language it's hard” (Africa House). Some participants felt that the way the questions are worded on the travel diary are complex and potentially confusing to anyone who does not speak English or Spanish as their first language. Additionally, these complicated questions asked for detailed information and might leave potential respondents feeling nervous that they may misunderstand and give their private information to the wrong person/agency.

If I were to translate this for the families that I work for, they ask you much more questions than you ask them. So if you ask them 5 questions, they'll ask you 10 which is what you try to keep it simple and clear because they're really scared because of all of the language barriers they want make sure that whatever information they give you is clear; they're very protective of their information because they know there's a reason. (Africa House)

When participants do not already speak or read the language of the survey, they have a heightened awareness of ensuring they understand the questions completely before giving out information about themselves. Without clear instructions and explanation of the purpose, nonEnglish and Spanish speakers may refuse to participate for fear they are being misguided. This concern is amplified when the surveys are simply mailed to households and there are few opportunities for face-to-face interaction and clarifying questions. 
Furthermore, simply translating the travel diary into various other languages is not enough. If the transportation study is going to truly reflect the communities it serves, it must also be accessible to those who do not read and folks who have a disability that prevents them from responding to a paper survey. As one participant explained:

Even those who don't read that language still need access to that information, so technology allows today to make information accessible in various ways, so government should not be limited to only one way of making information accessible. So that's the obligation of the government. (Africa House)

Translating the travel diary into a more diverse range of languages will not inherently make it representative; additional steps can be taken to capture the many different voices in these communities. 


\subsection{CONCLUSION: RECOMMENDATIONS TO ENHANCE EQUITY IN TRANSPORTATION SURVEY RESEARCH}

\subsubsection{Transparency in Data Collection}

Across all focus groups in this study, participants noted that they would not feel comfortable completing surveys unless there was a great deal of clarification about the purpose of the study, the entities that might use the data collected, and the rationale behind asking for certain kinds of highly detailed and personal information. In the future, survey designs should strive to clarify -in clear and direct language - who will use the data and why certain questions are important. This could mean that there are short explanations within a survey, a longer discussion of the purpose of the survey at the beginning, or more direct engagement with community members who are selected to participate in the study. Easier mechanisms to ask clarifying questions would be important.

Along with this, making data (and the procedures for data collection) from the study available to the public is of utmost importance. We would highlight the Puget Sound Regional Council's work to both recruit underrepresented groups in their most recent survey, along with their clear and easily accessible data and technical documents as a model to follow.

\subsubsection{Protection of Data and Privacy}

Given the amount and type of data that is often collected by household travel survey procedures, it should not be surprising that some individuals are curious about how information is stored and who has access to such information. For many participants in this study, issues of safety were raised when people considered their willingness to participate in a survey. Participants wanted additional information about how data would be stored, how their individual identities would be protected, and the extent to which certain state or federal agencies could access these materials. For many immigrants, they reported concerns about their personal information being shared with immigration officials in compromising or problematic ways. Efforts should be made not only to anonymize and protect all participants, but to clarify at the start of the survey what procedures are being used to protect participants.

\subsubsection{Community Engagement Throughout Data Collection Process}

During focus groups, many participants noted that they would have trouble completing a travel diary due to a range of issues (time required, assistance needed to identify street names or addresses). In the future, partnerships with key community organizations that are paid to host workshops to help complete surveys would be extremely beneficial. With more than 6,000 households in the greater Portland area participating in the survey, it would undoubtedly increase response rates to offer workshops at local libraries, community centers, or schools where local organizations could help those who have been selected to participate to complete the survey materials. This might require additional funds to compensate organizations for their time, as well as opportunities for participants to access child care or financial incentives in order to engage in this manner. However, such investments would likely yield not only higher response rates from 
underrepresented groups, but would also enhance the validity of the surveys completed in this manner and would likely reduce nonresponse issues.

\subsubsection{Reduce Language Barriers}

Efforts must be made to translate this survey into as wide a variety of languages as possible. While it may be impossible to provide a translation for all languages spoken in Portland, it is possible to work in partnership with local organizations to have surveys made accessible with the assistance of a translator in a workshop setting. In Section 5.1.6 below we also offer suggestions that could make an English-language survey more accessible to those with limited English proficiency.

\subsubsection{Collecting Travel Behavior Data Via GPS Technology}

The use of GPS technologies to supplement or augment travel survey data collection has been suggested as a means of collecting more accurate and robust travel data (Gong, Chen and Lawson, 2010; Safri, Assemi, Mesbah, and Farreira, 2017; Zuo, Wei and Rohne, 2018). However, questions remain regarding the viability of such modes of data collection, as many individuals may be reluctant to share this data for research purposes. Given the above-noted barriers to collecting survey data in more traditional ways, the research team was interested in asking focus group participants about their thoughts on the use of GPS technologies.

Participants had mixed feelings about city and state agencies tracking and collecting their GPS data for the purposes of a transportation survey. About half of participants who voiced an opinion were open to the idea, although some with hesitation, while the other half were strongly opposed and wouldn’t allow their location data to be tracked under any circumstances.

Five participants noted that they would allow their location to be tracked without hesitation. Their primary reason for this was to make it easier to complete the travel diary, given their concerns about the difficulty and confusing nature of the transportation diary. One participant noted that Google already collects her location data, so she had fewer reservations about the state or city doing so for a transportation survey.

I use my GPS to find places because even though I've been in Portland all my life I still have trouble finding the addresses and so I do use my GPS and my location is already on. (Rockwood-English)

Three other participants were open to the idea of having their GPS data collected if certain conditions were met. For example, one participant would only be comfortable allowing the data collection if she could opt in, stating:

It would have to be something that I would authorize. Like I want to authorize it, I don't want it to just be like my phone's in the car and they just track where I'm going. And for survey purposes, you know if I want to opt in to that then okay for survey purposes.

(Beaverton) 
Another participant would consider allowing her location data to be collected if she was told up front of the study's purpose, as noted in this exchange with the facilitator:

Participant: I would say really, again, it depends on the end goal. Like, what are you tracking me for? Is it for distance?

Facilitator: So, if you had information up front like this is the reason we want to do this and you agreed with that reason, then maybe that's some you'd consider?

Participant: Yeah

(Beaverton)

This participant not only wanted to know the purpose of the data collection, but also needed to agree with and support the study's objective.

Eight other participants, however, were quick to say they would not allow their GPS data to be tracked for a travel survey under any circumstances. Many of the concerns stemmed from other government agencies accessing the data. Several participants in the Spanish Rockwood focus group specifically discussed their and their family's legal status and were worried about ICE obtaining the information:

Again, if its information for public transportation yes, maybe, but if they might share it with other agencies then no, like the other lady said earlier... with ICE and everything, we are just waiting to see what happens so then no, because who would like to put themselves at risk? (Rockwood-Spanish)

Given the current political climate and the uncertainty of immigration policy, most of our Spanish-speaking participants said they would not be willing to permit access to GPS tracking. Other participants noted it was “too big brother" (Beaverton) and explained they didn't have their location setting enabled because they didn't even want their phone manufacturer collecting their data or location information. When asked if any incentives would change her mind, one participant made it clear she would never agree under any circumstances: "to track me, GPS me? No, not at all, never" (Rockwood-English).Thus, the use of GPS technologies is not a perfect solution to the above-noted barriers to completion; some individuals may be interested in the use of a smartphone app or device, but many people of color in this study expressed significant concerns about how sharing this data with a state or city agency would impact their well-being.

\subsubsection{Suggestions for Enhancing Access to Travel Survey Research Amongst Those with Limited English Proficiency}

In this section the summary findings from the supplemental data collection with the community organization People, Places, Things are presented. Though not exhaustive, this section is meant to offer some insights about adapting survey questions for English learners - this may be highly relevant where translation into multiple languages is not possible or feasible. The procedures for data collection that contributed to these suggestions can be found in Section 2.3.5. 


\subsubsection{Design Elements}

- Reduce the number of words on a page; consider wider spacing between concepts or sections.

- Increase the use of images to convey ideas, particularly icon-driven imagery that has universal meaning.

- For travel behaviors, consider how understandings of geography and space can vary across cultures: many people "know" the routes they take, but may not know the names of cross streets or the specific locations of places they go. What are some alternative ways of getting at spatial locations without knowing addresses? How can visuals be incorporated in this way?

- Avoid primary reliance on online surveys: In general, ESL participants had lower levels of technological proficiency and demonstrated a reluctance to complete the online survey model provided by the research team, as compared to paper surveys. This may be due in part to broader concerns about surveillance in the U.S. and lack of familiarity with online survey research.

\subsubsection{Specific Phrasing Suggestions}

Measuring Race \& Ethnicity: Racial and ethnic categorizations that have meaning in the U.S. may not have the same meaning for immigrants. Consider asking for clarifying information about country of origin or language(s) spoken at home, or offering open-ended options asking people to describe their race, ethnicity, and language/dialect.

Measuring Educational Background: Standard ranges of educational attainment may not translate easily cross-culturally. Consider more asking about the number of years of education completed in addition to/instead of asking about degrees or levels of education.

\section{Avoiding Confusing Words and Phrases}

Some common survey terms like "household" are not universally translatable. If an English learner is taking a survey in English, these concepts may require additional explanation to prepare participants so they can answer those questions.

In this study, we tested multiple ways of asking questions about income ( monthly household income; annual household income) and monthly income estimates proved the most likely to be understood. However, the non-nuclear nature of many immigrant households makes it so that household-level measurements are difficult for many people to answer.

Survey designers could also consider asking a series of questions that eventually get to the answer they are looking for. For example, rather than just asking for "annual household income," consider how the following series might yield a more accurate answer:

- How many people live in your house?

- How many people have an income?

- What is the average monthly income of person 1,2 , 3, etc. 
- Are you receiving any public assistance?

- Are you supporting any other children outside your home?

- Are you supporting any other adults outside your home?

- Do you have any people in your house who pay rent but don't share food?

\subsubsection{Personal Information Concerns}

As noted in the findings above, many participants enjoyed answering questions about themselves, but remained skeptical of surveys that asked overly specific questions. As such, survey designs might consider alternative choices to entering a home address (useful for undocumented individuals who are reluctant to share personal information) and might also consider options to participate in surveys without including overly specific personal or demographic data.

When being told that they were being asked to participate in a research study to help improve future survey designs, participants were very happy to participate, but concerns about the survey being used by the government were raised; therefore, efforts to encourage participation from immigrant groups should be attentive to concerns about trust and the protection of research concerns. Efforts must be made to communicate how data would be stored and used, and what the purpose of the survey is.

\subsubsection{Concluding Thoughts}

In sum, our quantitative findings demonstrate that previous OHAS data collection methods misrepresented vulnerable Nonwhite populations. They are the same populations who may be the most reliant upon public transportation infrastructure and amenities. Through targeted recruitment of the same populations who were underrepresented in the 2011 OHAS study, we directly engaged community members about why they might/might not complete a household travel survey.

Our findings suggest that efforts to have more representative survey participation must be made throughout the survey design and participant recruitment process. These include being more thoughtful about the language used in the survey itself, and providing more opportunities for assistance in completing a survey. Additionally, translating survey materials into a wider range of languages, increasing engagement with community organizations, taking precautions related to data privacy and protection, and being clearer and more forthright about the purpose of the survey and which city or state agencies might have access to data may be key avenues toward improving transportation survey design and participant recruitment. Though many of the suggestions offered here may require the investment of additional time or money, a failure to consider the very real barriers to survey completion that marginalized community members face risks ongoing inequities in survey representation. As many of the nation's long-range transportation plans rely upon household travel survey data, it is of utmost importance that participation of our most vulnerable community members in these surveys is prioritized. 


\subsection{REFERENCES}

Barcelos, Chris. Culture, Contraception, and Colorblindness: Youth Sexual Health Promotion as a Gendered Racial Project. Gender \& Society 32, no. 2 (2018): 252-273.

Bricka, Stacey. Daily Travel in Oregon: A Snapshot of Daily Household Travel Patterns. Oregon Department of Transportation, 2018.

Clifton, Kelly, Patrick Singleton, Christopher Muhs and Robert Schneider. "Development of Destination Choice Models for Pedestrian Travel.” Transportation Research Part A: Policy and Practice 94, (2016a): 255-265.

Clifton, Kelly, Patrick Singleton, Christopher Muhs, Robert Schneider. "Representing Pedestrian Activity in Travel Demand Models: Framework and Application.” Journal of Transportation Geography 52, (2016b): 111-122.

Dillman, Don, Jolene Smyth, and Leah Melani Christian. Internet, Phone, Mail, and MixedMode Surveys: The Tailored Design Method. Hoboken, NJ: John Wiley \& Sons, 2014.

Downey, Liam. “Using Geographic Information Systems to Reconceptualize Spatial Relationships and Ecological Context.” American Journal of Sociology 112, no. 2, (2006): 567-612.

Forkenbrock, David and Schweitzer, Lisa. "Environmental Justice in Transportation Planning.” Journal of the American Planning Association 65, no. 1 (1999): 96-111.

Geller, Roger. "What Does the Oregon Household Activity Survey Tell Us About the Path Ahead for Active Transportation in the City of Portland?” Portland, OR: Portland Bureau of Transportation, 2013.

Glaser, BG and AL Strauss. The Discovery of Grounded Theory: Strategies for Qualitative Research. Chicago: Aldire, 1967.

Gong, Hongmian, Cynthia Chen, Evan Bialostozky and Catherine Lawson. “A GPS/GIS Method for Travel Mode Detection in New York City.” Computers, Environment and Urban Systems, 36, no. 2, (2012): 131-139.

Karner, Alex and Niemeier, Deb. "Civil Rights Guidance and Equity Analysis Methods for Regional Transportation Plans: A Critical Review of Literature and Practice.” Journal of Transport Geography 33 (2013): 126-134.

Manson, Steven, Jonathan Schroeder, David Van Riper, and Steven Ruggles. "IPUMS National Historical Geographic Information System: Version 12.0 [Database]." Minneapolis: University of Minnesota (2017): 39.

Martens, Karel. Transport Justice: Designing Fair Transportation Systems. New York: 
Routledge, 2017.

Martens, Karel, Golub, Aaron and Robinson, Glenn. “A Justice-Theoretic Approach to the Distribution of Transportation Benefits: Implications for Transportation Planning Practice in the United States.” Transportation Research Part A: Policy and Practice 46, no. 4 (2012):684-695.

McKenzie, Brian S. "Neighborhood Access to Transit by Race, Ethnicity, and Poverty in Portland, OR." City \& Community 12, no. 2 (2013): 134-155.

NuStats. Oregon Household Activity Survey: Region 2 Final Report. Austin, TX: NuStats, 2010.

Paleti, Rajesh and Lacramioara Balan. "Misclassification in Travel Surveys and Implications to Choice Modeling: Application to Household Auto Ownership Decisions.” Transportation (2017): 1-19.

Riandey, Benoît and Martine Quaglia. “Surveying Hard-to-Reach Groups.” In Transport Survey Methods: Keeping Up With a Changing World, edited by Patrick Bonnel, Martin Lee-Gosselin, Johanna Zmud, and Jean-Loup Madre, 127-144. United Kingdom: Emerald Group Publishing Limited, 2009.

Rizzo, Louis and Gregory Erhardt. Sample Size Implications of Multi-Day GPS-Enabled Household Travel Surveys. National Academies Press, 2016.

Safri, Hamid, Behrang, Assemi, Mahmoud Mesbah and Luis Farreira. (2017). "An Empirical Comparison of Four Technology-Mediated Travel Survey Methods.” Journal of Traffic and Transportation Engineering (English Edition), 4, no. 1, (2017):80-87.

Selby, Brent, Anurag Komanduri, Edward Brown, Vladimir Livshits. “Applying GeographicBased Demographic Targeting in Household Travel Survey Sampling Plans: Case Study from the Phoenix, Arizona Region.” Paper presented at the Transportation Research Board 96 ${ }^{\text {th }}$ Annual Meeting, Washington D.C., January, 2017.

Shaghaghi, Abdolreza, Raj Bhopal and Aziz Sheikh. "Approaches to Recruiting 'Hard-toReach Populations into Research: A Review of the Literature.” Health Promotion Perspectives, 1, no. 2 (2011): 86-94.

Strauss, Anselm and Juliet Corbin. Basics of Qualitative Research Techniques and Procedures for Developing Grounded Theory ( $2^{\text {nd }} e d$.). London: Sage Publications, 1999.

Tourangeau, Roger. “Defining Hard-to-Survey Populations.” In Hard-to-Survey Populations, edited by Roger Tourangeau, Brad Edwards, Timothy Johnson, Kirk Wolter and Nancy Bates, 3-20. United Kingdom: Cambridge University Press, 2014.

Zuo, Ting; Heng Wei and Andrew Rohne. "Determining Transit Coverage by Non-Motorized 
Accessibility to Transit: Case Study of Applying GPS Data in Cincinnati Metropolitan Area.” Journal of Transport Geography, 67 (2018): 1-11. 